\title{
A cidade moderna contada por Sophia de Mello Breyner Andresen
}

\section{The modern city told by Sophia de Mello Breyner Andresen}

Carlos Roberto dos Santos Menezes

Universidade Federal do Rio de Janeiro (UFRJ), Rio de Janeiro, Rio de Janeiro / Brasil carlosroberto_sm@hotmail.com

Resumo: A partir das considerações de Eduardo do Prado Coelho em "Sophia, a lírica e a lógica" (1980); Sofia de Sousa Silva, "Sobre a paisagem em Sophia de Mello Breyner Andresen"; Helena Carvalhão Buescu, Cristalizações: fronteiras da modernidade (2005), entre outros, o presente texto busca compreender como a imagem da cidade contemporânea é representada na escrita de Sophia de Mello Breyner Andresen como forma de intervenção crítica sobre uma realidade hostil, cruel e indiferente. Partindo da leitura do conto "O homem", extraído do livro Contos exemplares, pretendemos averiguar de que modo a sociabilidade sofre degeneração no espaço urbano e quais são os meios de resgatar a humanidade aparentemente perdida pelas paredes da cidade.

Palavras-chave: Sophia de Mello Breyner Andresen; cidade; O homem; Contos exemplares; injustiça.

Abstract: From the considerations of Eduardo do Prado Coelho in "Sophia, a lírica e a lógica" (1980); Sofia de Sousa Silva, "Sobre a paisagem em Sophia de Mello Breyner Andresen"; Helena Carvalhão Buescu, Cristalizações: fronteiras da modernidade (2005), among others, this text seeks to understand how the image of the contemporary city is represented in the writing of Sophia de Mello Breyner Andresen as a form of critical intervention over a hostile, cruel and indifferent reality. Starting from the reading of the short story "O homem", extracted from 
the book Contos exemplares, we intend to find out how sociability suffers degeneration in urban space and what are the means of rescuing the humanity apparently lost by the walls of the city.

Keywords: Sophia de Mello Breyner Andresen; city; O homem; Contos exemplares; injustice.

Data de submissão: 8 de agosto de 2018

Data de aprovação: 8 de janeiro de 2019

Dentre as paisagens que permeiam o imaginário de Sophia de Mello Breyner Andresen, a cidade passa a ser um tema cada vez mais presente na sua escrita. Esta imagem, para aqueles que conhecem a obra da autora em questão, lhe é deveras cara, afinal como aponta Sofia de Sousa Silva (2008, [s.p.]), "a cidade se torna um ponto ambíguo e problemático na obra de Sophia [...] e na maior parte das vezes em que isso acontece, é em tom negativo". Nas vezes em que a obra da autora se deteve no espaço citadino, este é tomado por traços negativos que imperam na linguagem que procura reconstruir, por meio das palavras, as implicações que a cidade inocula no sujeito. Entretanto, como bem observou Eduardo Prado Coelho no ensaio "Sophia, a lírica e a lógica", há apenas um exemplo que escapa do lugar ambíguo e problemático e de onde o traço negativo se esvai: Brasília, como exemplo de cidade tipicamente moderna possui uma configuração própria no universo poético da autora.

Brasília torna-se um espaço singular na obra de Sophia, pois para além de uma cidade que designa o caos, a sujeira, um espaço ruidoso ou o local da desigualdade, ela, por sua idealização, surge como o lugar de um tempo que combate o caos da história por ter sido "desenhada por Lúcio Costa Niemeyer e Pitágoras", ${ }^{1}$ um projeto estético criado a partir da "lógica e lírica" cuja harmonia relembra a polis Grega. Em outras palavras, para a autora, Brasília vem a ser a cidade planejada arquitetonicamente: "é uma cidade que não resulta de um trabalho

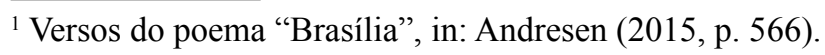


do tempo, involuntário e obstinado, inconsciente e tumultuoso. Pelo contrário, Brasília é uma afirmação da vontade do homem contra as contingências da história, é uma vitória do número sobre o barroco". (COELHO, 1980, p. 25).

Na contramão do que a cidade de Brasília representa para Sophia, voltemos nossos olhos para um poema cuja cidade designa exatamente o lugar ambíguo e essencialmente negativo, leiamos:

\section{CIDADE}

Cidade, rumor e vaivém sem paz das ruas,

Ó vida suja, hostil, inutilmente gasta,

Saber que existe o mar e as praias nuas,

Montanhas sem nome e planícies mais vastas

Que o mais vasto desejo,

E eu estou em ti fechada e apenas vejo

Os muros e as paredes, e não vejo

Nem o crescer do mar, nem o mudar das luas.

Saber que tomas em ti a minha vida

E que arrastas pela sombra das paredes

A minha alma que fora prometida

Às ondas brancas e às florestas verdes.

"Cidade", poema extraído do livro Poesia (1944), exemplifica a forma como o discurso andresiano constrói, por meio da linguagem poética, a imagem da cidade moderna. $\mathrm{O}$ espaço urbano vai sendo tecido por uma dicção que remonta à memória de uma cidade industrial, cujo movimento incessante dos seus transeuntes lhe congrega a ideia de "rumor" e de um "vaivém sem paz". O espaço é um organismo vivo que se mantém em constante movimento, mas um movimentar-se que retira a paz, impede o silêncio e rouba do sujeito a harmonia, já que instaura um caos capaz de transformar a vida em algo "gasto", "hostil" e "sujo". O sujeito que diz esta cidade é um ser consumido pela melancolia, pois, ao olhar para o espaço citadino, consegue compreender a precariedade da sua alma que reside aprisionada entre muros e paredes capazes de impedirem o alcance da visão em direção ao esplendor natural do mar e as fases da lua, como possibilidades de evasão desse estado de corrosão que se instaura dentro do próprio sujeito. 
O espaço descrito no poema é retratado de maneira violenta, mas uma violência quase velada devido à economia da linguagem poética que, por meio de imagens negativas, demonstra o estado de angústia do sujeito poético impossibilitado de atingir os seus anseios anímicos. A cidade configura-se como o locus horrendus capaz de usurpar a vida, sugá-la e emparedá-la de modo que a natureza esteja para fora da sua geografia citadina. O mar, a praia, as planícies, as fases da lua e as florestas, caracterizam o locus amoenus que é posto de lado para em lugar prevalecer a hostilidade, a desigualdade, a sujeira e as sombras.

A cidade mostra-se como um espaço em tensão, capaz de exercer uma atração "magnética" no sujeito, além de ser composto por "vozes", "ruídos", "sombras", "luzes", "paredes", "muros", que designam a degradação por meio da "sujeira", da "hostilidade":

\section{CIDADE}

As ameaças quase visíveis surgem

Nascem

Do exausto horizonte mortas luas

E estrangulada sou por grandes polvos

Na tristeza das ruas (ANDRESEN, 2015, p. 474).

O sujeito sente-se estrangulado numa cidade tentacular que se mostra revestida de ameaças cujo nascimento se dá desde o horizonte. $\mathrm{O}$ espaço urbano, portanto, é aquele que congrega em si a crueldade e a violência, oprime quem nele reside e transita, demonstra desconcerto com a natureza e provoca a ruína e a melancolia.

A cidade não é um espaço exclusivo da poesia de Sophia, a sua prosa dedica algumas linhas a este lugar tenso e ambíguo na sua ótica, como é o caso do conto "O homem", extraído do livro Contos exemplares (1962). ${ }^{3}$ Esta narrativa consiste num relato de uma narradora-personagem que está a caminhar pelo passeio com o intuito de encontrar alguém, porém, no meio da multidão surge a figura de um homem carregando uma criança no colo cuja beleza chama a sua atenção. A partir deste encontro,

\footnotetext{
${ }^{2}$ Há em vários poemas de Sophia a presença de cidades luminosas, mas esta luz que emana não necessariamente é positiva, pois como vimos no poema "Cidade" não é possível ver a lua, exatamente pelo fato de que a iluminação elétrica do espaço urbano impede a contemplação da iluminação natural da lua e das estrelas.

${ }^{3}$ Primeira edição do livro Contos exemplares.
} 
observamos a desarticulação da ordem citadina e as suas implicações na personagem.

O espaço nos é apresentado quase como um poema, pois a sua descrição vai sendo composta através de imagens sintaticamente concisas, vejamos:

Era uma tarde do fim de Novembro, Já sem nenhum Outono. A cidade erguia as suas paredes de pedras escuras. O céu estava alto, desolado, cor de frio. Os homens caminhavam empurrandose uns aos outros nos passeios. Os carros passavam depressa. (ANDRESEN, 1970, p. 153).

O conto abre-se com um registro temporal preciso - "era uma tarde de fim de Novembro" - entretanto, este mesmo registro temporal instaura na narrativa o lugar da transitividade entre as estações do ano que é anunciada pelo fim do Outono e o início do Inverno. A temporalidade demarcada anuncia uma mudança cujo movimento narrativo irá desenvolver-se ao longo de suas linhas. Mas primeiro, vejamos como a cidade vai sendo descrita.

Parece que a voz narrativa ecoa os versos de Sophia ao materializar a figura da cidade no espaço textual. Elementos explorados pela poesia são agora invocados pela prosa, de modo que "as paredes de pedra escura" funcionam como uma forma de encarceramento, tal qual o movimento contínuo da multidão que designa a vivacidade do espaço urbano. No entanto, na narrativa esse espaço demarca de forma acentuada a agressão sugerida pelo movimento caótico da multidão durante todo o texto e a indiferença com relação ao outro. A apatia, por sua vez, ultrapassa o limite do imanente e atinge o transcendente ao ponto que o "céu" - "desolado" e "frio" - implica uma problemática visão do sagrado que se revelará indiferente ao sofrimento humano:

Era aquela a posição da cabeça, era aquele o olhar, era aquele o sofrimento, era aquele o abandono, aquela a solidão.

Para além da dureza e das traições dos homens, para além da agonia da carne, começa a prova do último suplício: o silêncio de Deus.

E os céus parecem desertos e vazios sobre as cidades escuras (ANDRESEN, 1970, p. 159 - grifos nossos). 
A economia linguística também nos remonta à construção poética, na medida em que a descrição do espaço vai sendo tecida na malha textual por meio de imagens de cunho metafórico e metonímico. Esse discurso designa em poucas linhas a precisão de uma cidade moderna, cujo furor reside no movimento contínuo que aqueles que transitam pelo passeio exercem, tal qual o movimento mecânico dos carros que passavam depressa. Em termos de espelhamento, entre a multidão e a máquina não há distinção.

A caracterização da cidade ocorre por metonímia a partir daquilo que a mantém como um organismo vivo, em outras palavras, o espaço citadino do conto corresponde a uma cidade moderna cuja engrenagem encontra-se na movimentação da população que, ao movimentar-se pelas ruas num único movimento uniforme, cria o estatuto de multidão. Desta forma, a cidade distanciada do céu é aquela que possui movimento próprio e constante - onde a "multidão não parava de passar" -, tendo a capacidade de arrastar a narradora-personagem que permanece parada observando o homem com a criança no colo. Esse espaço, caracterizado pelo "empurra", "separa", marca o movimento da multidão equivalente, metaforicamente, a uma "onda de gente" - massa homogênea impossível de diferenciação, composta metonimicamente por "ombros" e "cabeças" (ANDRESEN, 1970, p. 158) - fragmentos de corpos ou homens partidos.

A precisão da linguagem que se ocupa do espaço urbano não só traz de volta a memória das cidades que outrora são evocadas nos poemas, como é revisitada pela mesma sensação de hostilidade, abandono, sujeira, na medida em que ela é composta por muros, paredes, é uma "cidade escura" cuja multidão lhe permite um movimento próprio, mas que estilhaça a identidade e singularidade do sujeito. No passeio, a cidade "empurra" o sujeito e o tempo, e esse não poderia ser outro a não ser o mesmo tempo do "relógio [que] bateu horas" (ANDRESEN, 1970, p. 157), o mesmo tempo que dita a ordem do capital numa cidade moderna.

Neste cenário pintado com tinta negra, surgem três personagens: a narradora-personagem que está no passeio indo ao encontro de alguém, a criança e o homem. Em termos de descrição, pouco sabemos a respeito da protagonista, contudo, a criança e o homem possuem descrições físicas bem precisas. A princípio, destaca-se a beleza aliada à inocência, inerente à criança: 
Havia muita gente na rua naquele dia. Eu caminhava no passeio, depressa. A certa altura encontrei-me atrás de um homem muito pobremente vestido que levava ao colo uma criança loira, uma daquelas crianças cuja beleza quase não se pode descrever. É a beleza de uma madrugada de Verão, a beleza de uma rosa, a beleza do orvalho, unidas à incrível beleza de uma inocência humana (ANDRESEN, 1970, p. 153-154).

O homem, por sua vez, é descrito da seguinte maneira:

Era um homem extraordinariamente belo, que devia ter trinta anos e em cujo rosto estavam inscritos a miséria, o abandono, a solidão. O seu fato, que tendo perdido a cor tinha ficado verde, deixava adivinhar um corpo comido pela fome. O cabelo era castanhoclaro, apartado ao meio, ligeiramente comprido. A barba por cortar há muitos dias crescia em ponta. Estreitamente esculpida pela pobreza, a cara mostrava o belo desenho dos ossos. Mas mais belos do que tudo eram os olhos, os olhos claros, luminosos de solidão e de doçura. No próprio instante em que eu o vi, o homem levantou a cabeça para o céu (ANDRESEN, 1970, p. 154-155).

Em consonância com os atributos físicos da personagem, somos expostos ao estado emocional de devastação em que esta se encontra, a partir de elementos como "beleza", "miséria", "abandono" e "solidão", que destacam a sua exclusão de uma sociedade que se deseja justa e equânime.

Helena Carvalhão Buescu, no ensaio "Sophia no país das maravilhas" (2005), chama a atenção para a temática do "olhar e ser olhado", inerente à questão da modernidade em Baudelaire, interpretada por Benjamin. Segundo as palavras do filósofo citadas por Buescu: "quem é olhado ou se crê olhado levanta os olhos" (BENJAMIN apud BUESCU, 2005, p. 58). Esse "jogo fundador da existência" está presente em "O Homem" de forma irretocável. A imagem do sujeito sofredor ultrapassa os olhos desatentos daqueles que formam a multidão e se fixa na retina da narradora-personagem, transformando-a naquela que vê e que repara na existência do sujeito sofredor. É por meio do olhar que a narradora passa a ver e a escutar o mundo e a compreender todas as suas injustiças.

Ao observar e relatar a sua experiência, a personagem instaura uma forma de "estar atenta ao mundo como forma de estar atento a si. Escutar o mundo para poder falar" (BUESCU, 2005, p. 57), funcionando 
como "catalisadora da existência e da experiência existencial" (BUESCU, 2005, p. 59). A própria Sophia se debruça sobre a questão do olhar e diz: "aquele que vê o espantoso esplendor do mundo é logicamente levado a ver o espantoso sofrimento do mundo. Aquele que vê o fenómeno quer ver todo o fenómeno. É apenas uma questão de atenção, de sequência e de rigor" (ANDRESEN, 2015, p. 893).

Observa-se que a própria narradora não é sequer vista pelo homem, mas aos poucos vai sendo percebida pela multidão: "as pessoas que não viam o homem começavam a ver-me a mim. Era impossível continuar assim parada" (ANDRESEN, 1970, p. 157) - o movimento contrário realizado pela personagem implica numa ação ambígua na qual não só observa o homem e a multidão como também é percebida pela massa uniforme. Contudo, é somente através do olhar que busca romper o silêncio na tentativa de verbalizar aquilo que lhe fixa aos olhos que obtemos uma consciência atenta capaz de captar a existência física e emocional do sujeito e traduz o seu encontro com o mundo.

A composição das personagens é o resultado de um laborioso trabalho de linguagem que, na sua economia, proporciona uma construção, cujo sentido vai sendo espalhado pelo texto como pistas a serem detectadas. A criança carregada pelo homem e o próprio chamam a atenção da narradora-personagem, desviando o seu olhar mecânico e desarticulando o seu movimento com o da multidão. Ambos vêm a ser dotados de "uma beleza quase não se pode descrever"; essa descrição que caminha para o sublime é impossível de ser verbalizada, resultando na necessidade de uma outra linguagem capaz de poder dizer aquilo que o olhar da narradora capta não só ao ficar "um momento preso na cara da criança", como também ao fixar o olhar do homem que se eleva para o céu. A busca de uma dicção possível resulta, inclusive, na construção alegórica: ao tentar descrever a figura da personagem como "uma criança loira" e com a "incrível beleza duma inocência humana", a narradorapersonagem acaba por aproximá-la da imagem de um anjo, e, ao detectar a direção do olhar do homem miserável para o "céu", insinua a tentativa vã do sujeito de apelar a um ser transcendente, localizado nas alturas um possível contato com o sagrado que se revelará inoperante na forma de um silêncio ou omissão. O que a personagem-narradora, atenta ao real, vê é o imanente, a realidade factual que a cerca, com toda a sua concretude. Dessa forma, Sophia, através da narradora, "doa a sua voz para ressaltar a "veemência das coisas" (BUESCU, 2005, p. 60), confere 
visibilidade a um acontecimento que não é notado cotidianamente - um homem à deriva nas ruas da cidade imerso em sua solidão e abandono.

A criança, ao contrário do que se pode esperar da presença de um anjo como aquele que traz uma mensagem divina, possui na narrativa a função de desautomatização do movimento da cidade, pois é por meio da sua presença no centro da multidão que o olhar da protagonista se dispersa e centra-se na figura da criança para chegar à figura do homem. É, portanto, a partir da sua imagem que se estabelece o elo entre a narradorapersonagem e o homem que caminha lentamente pelo passeio, além de ser, também um contraponto com a figura da criança, que estabelece uma aproximação de um ser angelical capaz de desencadear a transformação do invisível em visível, da harmonia, da beleza, do sublime e da inocência humana que o espaço da cidade ainda não transformou em indiferença.

O homem, por sua vez, é o visível que se torna invisível na massa homogênea que é a multidão citadina, cujo olhar humano acostumado com a ruína, a dor e o sofrimento não mais se sensibiliza com a dor do outro. Entretanto, é através da narradora-personagem que essa figura emerge da imensidão do "mar de concreto"4: "ninguém o via caminhando lentamente, tão lentamente, com a cabeça erguida e com a criança nos braços rente ao muro de pedra fria" (ANDRESEN, 1970, p. 156-157). Esse corpo ignorado é descrito por meio de metonímia que não só fala de si mas, também, fala do ser humano. O homem é aquele que, para além da sua singularidade por ser "extraordinariamente belo" (ANDRESEN, 1970, p. 154), possui em seu rosto a inscrição da miséria, do abandono e da solidão. A enumeração capaz de caracterizar a personagem torna-se a descrição da ação humana no mundo, o sujeito da cidade não mais é capaz da comunhão, do afeto, pois o espaço urbano o hostiliza, o faz ter uma vida gasta, miserável, suja, cuja própria miséria impede a compaixão.

\footnotetext{
${ }^{4}$ Há no conto uma comparação bastante curiosa em que a narradora personagem aproxima o movimento da cidade feito pela multidão com a imensidão do mar. Diferente da conotação que a imagem marítima possui na poesia de Sophia, como algo libertador, natural, harmônico - como é o caso do poema "Cidade" lido anteriormente, no conto em questão esse paralelismo enfatiza a dimensão da quantidade de cidadãos no passo e a força do movimento: "Então, como o nadador que é apanhado numa corrente desiste de lutar e se deixa ir com a água, assim eu deixei de me opor ao movimento da cidade e me deixei levar pela onda de gente para longe do homem." (ANDRESEN, 1970, p. 157 - grifos nossos).
} 
A descrição física do homem pela narradora-personagem vai sendo construída numa forma bastante curiosa, pois através de paradoxos, que ao invés de se excluir passam a se complementar, ocorre o desvelamento de uma violência ${ }^{5}$ exercida pelo espaço citadino onde o corpo do sujeito torna-se a representação das marcas da crueldade. Embora a personagem seja composta de modo que o leitor sinta-se empático com a sua figura, para além dos traços positivos e do tom aparentemente brando da narrativa, partes da descrição da personagem apontam para uma crueldade velada e para a violência humana, pois "a sua cara escorria sofrimento. A sua expressão era simultaneamente resignação, espanto e pergunta" (ANDRESEN, 1970, p. 155). A aparente simplicidade da linguagem adotada pela voz narrativa passa a filtrar a violência revelando-a quase que indiretamente por meio da descrição do homem. A crueldade, portanto, mostra-se de forma ontológica na figura do sujeito que se encontra para fora do movimento da multidão, ${ }^{6}$ já que o ato de sofrer está tanto ligado à existência quanto à miséria do corpo humano.

$\mathrm{O}$ discurso narrativo faz com que tanto a violência do espaço citadino, quanto a crueldade humana sejam um modo de estar em linguagem, na medida que estes traços não constituem necessariamente o tema do relato, sendo assim "a crueldade não está em mimetizar uma realidade cruel e sua violência, mas na capacidade da linguagem de não essencializá-la" (GOMES, 2004, p.145).

A simplicidade da forma do relato proporcionou a construção de cenas que denotam a violência do espaço e a crueldade dos homens sem necessariamente serem representados atos de barbárie. A morte que atinge o corpo do homem, inclusive, é relatada num viés que o sangue verdadeiro não é suficiente para demonstrar o horror, mas, sim, a indiferença dos homens que supera a fragilidade do corpo que padece de solidariedade e piedade. As pessoas que passam e que sequer percebem a existência dele

\footnotetext{
${ }^{5}$ A violência presente no espaço urbano é caracterizada através dos gestos da multidão, basta-nos lembrar que a narradora-personagem, por mais de uma vez, é "empurrada pela multidão", cuja força dos "ombros mais fortes do que [os da personagem a] empurravam" (ANDRESEN, 1970, p. 160).

${ }^{6}$ Embora o sujeito esteja inserido no mesmo espaço físico que a multidão que ocupa o espaço urbano, ele é o único que caminha devagar e consegue desviar o olhar elevando-o para o céu em busca de resposta para o seu sofrimento, de modo a transgredir a norma do gestos da massa, o que acaba por retirá-lo do espaço da norma.
} 
e a sua devastação interior suspendem o movimento para admirarem-se com o teatro da morte.

Então a multidão parou e formou um círculo à volta do homem. Ombros mais fortes do que os meus empurram-me para trás. Eu estava do lado de fora do círculo. Tentei atravessá-lo, mas não consegui. As pessoas apertadas umas contra as outras eram como um único corpo fechado. À minha frente estavam homens mais altos do que eu que me impediam de ver. Quis espreitar, pedi licença, tentei empurrar, mas ninguém me deixou passar. Ouvi lamentações, ordens, apitos. Depois veio uma ambulância. Quando o círculo se abriu, o homem e a criança tinham desaparecido.

A multidão dispersou-se e eu fiquei no meio do passeio, caminhando para a frente, levada pelo movimento da cidade (ANDRESEN, 1970, p. 160-161).

O conto traz para dentro da narrativa o real que é conhecido e reconhecível pelo leitor. Isto ocorre, seja através das descrições e caracterizações das personagens, especificamente na apreensão dos gestos da criança e do homem, seja pela construção do espaço urbano por meio da linguagem. O movimento ininterrupto que caracteriza a multidão torna-se um índice de reconhecimento do interlocutor de que este espaço diz respeito, por exemplo, ao centro de uma cidade - como bem nos lembra a narradora: "A multidão não parava de passar. Era o centro do centro da cidade" (ANDRESEN, 1970, p. 156) -, sendo assim, há uma identificação estabelecida no conto entre o mundo ficcional e a realidade extratextual.

O olhar da narradora, ao mediatizar, no tecido narrativo, o sensível e o inteligível, ao inscrever a errância do sujeito e sua desolação, reflete a sua memória cultural. Há uma inegável analogia entre o sofrimento de Jesus Cristo e o do homem, em relação ao abandono de uma figura transcendente e onipotente que poderia salvá-lo, ao se deparar com uma situação-limite. Por isso, a aparição do homem, em meio ao caos citadino, evoca a figura de Jesus Cristo e as palavras bíblicas proferidas:

E do fundo da memória, trazidas pela imagem, muito devagar, uma por uma, inconfundíveis, apareceram as palavras:

- Pai, Pai, por que me abandonaste? 
Então compreendi por que é que o homem que eu deixara para trás não era um estranho. A sua imagem era exactamente igual à outra imagem que se formara no meu espírito quando eu li:

- Pai, Pai, por que me abandonaste? (ANDRESEN, 1970, p. 158-159).

Contudo, a morte de Cristo na simbologia judaico-cristã simboliza a redenção dos homens - "Ele morreu para nos salvar" -; na narrativa de Sophia de Mello Breyner isso não ocorre. Não há sequer a possibilidade de uma ressurreição e de um corpo insepulto.

Ao nos depararmos com o questionamento da narradora - "Como contar o seu gesto?" (ANDRESEN, 1970, p. 155), observamos a procura de uma linguagem capaz de dizer, de representar o inelutável: os gestos do homem, o espaço da cidade, a crueldade humana e a violência que se mostram como marcas físicas no corpo desse sujeito que sofre com as injustiças dos homens.

Em se tratando da ficção e da estreita relação entre estética e ética, inerente à obra de Sophia de Mello Breyner Andresen, não é apenas no conto "O homem" que se observa isso, mas também no "Jantar do Bispo", narrativa igualmente pertencente aos Contos exemplares em que nos deparamos com uma forte crítica social onde o mundo é dividido entre "os donos do poder" (representados pelo Dono da Casa e sua família) e os oprimidos (ao qual pertencem os criados, o pároco e os mendigos). Entre ambos os polos há o Padre de Varzim que põe em risco a "ordem da normalidade" e por isso precisa ser transferido para outra aldeia.

Se retomarmos o início da narrativa, verificaremos que o espaço citadino se encontra distante do céu, este, por sua vez mostra-se "alto, desolado, cor de frio". Há uma separação física no que diz respeito à verticalidade referente ao céu e à horizontalidade referente à terra. Chama-nos a atenção o uso do adjetivo "desolado" para a caracterização do céu que tanto pode indicar a tristeza de um dia frio, cinzento de inverno que se anuncia com a chegada de Dezembro, como, também, aponta para a questão do despovoamento, para a ausência de moradores, como se o espaço celeste estivesse vazio porque não há mais a presença do divino. A própria materialidade que separa o céu da cidade aponta para esta questão, afinal, o homem urbano, mecânico, parece esquecerse de Deus e é preciso um exercício da memória num tempo que não a possibilita para que esta relação possa ser recuperada. E, ao mesmo tempo, Deus parece esquecer-se dos homens: "com a cabeça levantada, 
o céu. Mas o céu eram planícies e planícies de silêncio" (ANDRESEN, 1970, p. 155). Há, portanto, uma ruptura nessa relação entre transcendente e imanente na contemporaneidade. No discurso fenomenológico da autora, que resgata resíduos do texto bíblico, instaura-se "a ausência necessária à presença - algo que a arte poética de Sophia "sabe discernir e comunicar". Tal reflexão crítica associa-se à "confluência do caos e da ordem, da transparência e da opacidade, de serenidade e da veemência, da crença e da descrença" inerentes à consciência da dimensão do mundo (BUESCU, 2005, p.63) tão bem compartilhada pela autora, ao estabelecer um diálogo com o texto bíblico:

E, consciente de que a composição do livro sagrado se faz através de uma linguagem cifrada - e que por isso mesmo só será compreendida por iniciados -, o artista, ao retomar certos temas, tem por objetivo reduzir a distância entre o intérprete inexperiente e uma narrativa cujos signos já não são legíveis. Assim, ao pretender, em alguns de seus passos, ser semelhante ao discurso bíblico, o tecer poético de Sophia revela a necessidade de revitalizar tal discurso em virtude da incompreensão do homem diante do código bíblico. Ao narrador compete, pois, atualizar a promessa da Bíblia; atento à mesmidade dos defeitos e pecados da humanidade, lê o mundo e re-organiza o universo bíblico em torno de elementos contemporâneos, evidenciando, através da semelhança, a eternidade dos conflitos (VASCONCELLOS, 1980, p. 140 - grifos do autor).

A reminiscência da narradora parte da sensação de que a figura do homem lhe soa como algo familiar, a memória passa a ser revisitada num ato de "[desenrolar] para trás o filme do tempo" (ANDRESEN, 1970 , p. 158). Curioso torna-se o fato de que o reconhecimento não parte de uma figura física, mas das palavras, pois é o verbo - o princípio originário - que surge do "fundo da memória" e faz com que a narradora compreenda "porque é que o homem que [ela] deixara para trás não era um estranho. A sua imagem era exactamente igual à outra imagem que se formara no [seu] espírito quando [ela leu]: - Pai, Pai, porque me abandonaste" (ANDRESEN, 1970, p. 158-159). A frase que surge do interior da narradora-personagem compõe a imagem que ela fizera na sua subjetividade do Cristo sofredor e faz com que a personagem aproxime esta figura do homem que caminha no passeio. Seja pelo sofrimento ou pela aparente materialização do divino, é através do discurso aprendido 
no Livro Sagrado que a tradição é recuperada por meio do ato da leitura e revisitada pelo exercício da memória. O livro, as palavras, o discurso surgem no espaço textual como o mecanismo de aprendizagem, e por meio destes é que a sabedoria da experiência de vida é transmitida de geração para geração.

E somente a palavra, a magia da palavra, é capaz de relembrar ao homem a necessidade da comunhão. O corpo do homem passa pela via crucis, é sacrificado, morre pacientemente esperando uma resposta para toda a sua dor, não a obtém, pois o céu está distante, permanece mudo, e os homens apenas apreciam o espetáculo da dor sem moverem-se. As horas batem no relógio, a cidade caminha, e fica a esperança do ensinamento.

Corri, empurrando quase as pessoas. Estava já a dois passos dele. Mas nesse momento, exactamente, o homem caiu no chão. Da sua boca corria um rio de sangue e nos seus olhos havia ainda a mesma expressão de infinita paciência.

A criança caíra com ele e chorava no meio do passeio, escondendo a cara na saia do seu vestido manchado de sangue (ANDRESEN, 1970, p. 160).

Não se pode perder de vista que o volume Contos exemplares é publicado em 1962, num período em que Portugal está imerso no poder totalitário do regime salazarista. As histórias que compõem o volume desvelam o desconcerto do mundo e denunciam suas implicações tanto no sujeito quanto na configuração dos espaços. Sendo assim, a denúncia provocada pelo discurso de Sophia busca artifícios para burlar o silêncio imposto pela censura e, a partir disso não nos soa estranho que haja uma busca por uma linguagem capaz de traduzir a experiência da insatisfação com o mundo.

Como é preciso revisitar o passado, resgatar os ensinamentos de outrora para recuperarmos o fio da humanidade que a cidade moderna teima em usurpar, "O homem" inicia-se com a frase "Era uma tarde do fim de Novembro..." (ANDRESEN, 1970, p. 153), passível de nos remeter à atemporalidade de um tempo mítico. O uso de tal locução, que designa um tempo circunstancial, nos remete à forma de inicialização, retida na memória, típica das histórias infantis: o "era uma vez". Essa aproximação não é gratuita, visto que o texto se constrói como uma alegoria, se quisermos, uma parábola. Tal arquitetura textual colabora com o projeto do livro que tem por objetivo contar histórias exemplares, 
como apontam não só o título do volume como a epígrafe de Cervantes retirada do "prólogo al lector", em Novelas Ejemplares: "Heles dado el nombre de ejemplares, y si bien lo miras no hay ninguna de quien no se pueda sacar um ejemplo".

Se olharmos detidamente para a composição do livro, nos deparamos com uma obra composta por sete narrativas, a simbologia dessa numeração nos sugere "o sentido de uma mudança depois de um ciclo concluído e de uma renovação positiva" (CHEVALIER; GHEERBRANT, 2009, p. 826). Sophia busca, através dos seus textos, uma possibilidade de saída diante das injustiças sociais, como aponta a dedicatória: "Para o Francisco, que me ensinou a coragem e a alegria do combate desigual" (grifos nossos). Contos exemplares, portanto consiste na tentativa da expansão desse ensinamento, por meio da literatura, de combater a desigualdade. Seja na poesia ou na prosa, é fundamental frisar que o texto andresiano consiste no conhecimento da existência do mundo e na consciência atenta da injustiça que reside no real. De modo geral há uma dimensão ética e política na escrita de Sophia de Mello Breyner Andresen. Numa passagem do seu texto lido por ocasião da entrega do Grande Prémio de Poesia atribuído ao Livro Sexto, e que mais tarde ficou conhecido como "Arte poética III", a autora nos diz:

A moral do poema não depende de nenhum código, de nenhuma lei, de nenhum programa que lhe seja exterior, mas, porque é uma realidade vivida, integra-se no tempo vivido. E o tempo em que vivemos é o tempo de uma profunda tomada de consciência. Depois de tantos séculos de pecado burguês a nossa época rejeita a herança do pecado organizado. Não aceitamos a fatalidade do mal. Como Antígona a poesia do nosso tempo diz: "Eu sou aquela que não aprendeu a ceder aos desastres." Há um desejo de rigor e de verdade que é intrínseco à íntima estrutura do poema e que não pode aceitar uma ordem falsa (ANDRESEN, 2015, p. 894)

Maria Elisabeth Graça de Vasconcellos, ao se debruçar sobre a questão exemplar dos contos de Sophia, comenta que "os Contos exemplares constituem passos de uma travessia em que o narrador, ao ler o mundo, procura iluminar os diferentes espaços marcados por injustiças sociais, é pela relação que tece entre (e com) as personagens que deixa gravada a denúncia" (1980, p. 142 - grifos da autora). No conto "O homem", a lição que obtemos advém da relação entre o sensível e 
o inteligível que parte da aproximação do discurso da narradora com a experiência vivida e rememorada não só do homem que caminha pela rua com uma criança no colo, cujo corpo é comido pela fome, e marcado pelo abandono, como também pela recuperação do ensinamento bíblico daquele que pela Paixão morreu em nome dos homens. Nesse sentido, retomo a frase escrita por José Saramago que ocupa o lugar de epígrafe de Ensaio sobre a cegueira (1995), retirada de um suposto livro dos conselhos: "Se podes olhar, vê. Se podes ver, repara".

Seja através da vida cotidiana, seja por meio da literatura, é necessário que recuperemos a nossa sensibilidade para com o homem comum, marcado pelo espaço da carência, da violência, representante dos humilhados e ofendidos, é preciso que sejamos capazes de promovermos uma mudança em busca da nossa humanidade cada vez mais esvanecida nas ruas, nos muros, nas paredes negras das cidades hostis e sujas. Há um hiato que separa os ensinamentos dos Contos exemplares de Sophia do romance "exemplar" de José Saramago, e isto ainda significa, pois ainda não fomos capazes de reparar que "muitos anos se passaram. $\mathrm{O}$ homem certamente morreu. Mas continua ao nosso lado. Pelas ruas" (ANDRESEN, 1970, p. 161).

\section{Referências}

ANDRESEN, Sophia de Mello Breyner. O homem. . In: Contos exemplares. Lisboa: Portugália, 1970. p. 151-163.

ANDRESEN, Sophia de Mello Breyner. Obra poética. Porto: Assírio \& Alvim, 2015.

ANDRESEN, Sophia de Mello Breyner. Cidade. In: . Obra poética. Porto: Assírio \& Alvim, 2015. p. 474.

BUESCU, Helena Carvalhão. Sophia no país das maravilhas. In:

Cristalizações: fronteiras da modernidade. Lisboa: Relógio D’Água Editores, 2005.

CHEVALIER, Jean; GHEERBRANT, Alain. Dicionário de símbolos. 23 ed. Coord. Carlos Susssekind. Trad. Vera da Costa e Silva et al. Rio de Janeiro: José Olímpio, 2009.

COELHO, Eduardo Prado. Sophia, a lírica e a lógica. Revista Colóquio/ Letras, Lisboa, n. 57, p. 20-35, set. 1980. 
GOMES, Renato Cordeiro. Narrativa e paroxismo - será preciso um pouco de sangue verdadeiro para manifestar a crueldade? In: DIAS, Ângela; GLENADEL, Paula (Org.). Estética da crueldade. Rio de Janeiro: Atlântica, 2004. p. 143-154.

SARAMAGO, José. Ensaio sobre a cegueira. São Paulo: Companhia das Letras, 1995.

SILVA, Sofia de Sousa. Sobre a paisagem em Sophia de Mello Breyner Andresen. In: CONGRESSO INTERNACIONAL DA ABRALIC, XI., 2008, São Paulo. Anais... São Paulo: ABRALIC, 2008.

VASCONCELLOS, Maria Elisabeth Graça de. A harmoniosa procura: A obra de Sophia de Mello Breyner Andresen e seu modelo cíclico. 1980. 269f. Tese (Doutorado em Letras Vernáculas) - Faculdade de Letras, Universidade Federal do Rio de Janeiro, Rio de Janeiro, 1980. 